\title{
The Coherency of Regulatory Requirements for Homeopathic Medicinal Products in the EU and the EAEU
}

\author{
Gunther Herr, Alexander Natz and Robbert van Haselen*
}

Similar to the EU model, a common market for medicinal products, including homeopathic medicinal products, is currently being established in the Eurasian Economic Union (EAEU). In this article, the requirements for regulatory market access of homeopathic medicinal products in the EU and in the EAEU are analyzed and compared. Difficulties in applying core requirements of both union laws correctly and coherently are identified and related proposals for a more coherent interpretation are made. Overall the communalities in both union laws contribute to market access and competition, but consistent interpretation of core terms in the regulatory framework by the Member States' competent authorities remains the main challenge.

\section{Introduction}

In 2014 the Eurasian Economic Union ('EAEU') was founded. The Agreement on Common Principles and Rules of Circulation of Medicinal Products within this union (the Agreement) provides for the establishment of a common market and free circulation of medicinal products. ${ }^{1}$ This process has continued with the adoption of unified requirements for medicinal products, ${ }^{2}$ which include homeopathic medicinal products. In the European Union (EU) the legislative process for homeopathic medicinal products started in 1990 with the objective to guarantee safety and quality and to permit patients' access to medicinal products of their choice. After providing a background on homeopathic traditions in the Member States and on the reasons and effects of the union legislation for homeopathic medicinal products (Sections II - III), this article compares and analyses their regulatory requirements for registration and authorisation (Sections IV to X). The difficulties in interpreting core requirements of both union laws correctly and coherently are addressed and concrete proposals for such interpretations are made. As further outlined in the Conclusion (Section XI) the laws in both unions for homeopathic medicinal products were carefully developed and are well-balanced. The commonalities between the requirements in both unions are helpful for pharmaceutical companies by allowing them to use their regulatory documentation in both unions and thus contribute to market access and competition. Taking into account the past experiences made in the EU and the new terminology recently introduced in EAEU law, achieving a coherent application of the union laws in practice is, however, seen as the main challenge for the regulators.

\section{Homeopathic Medicinal Products}

According to WHO's Glossary, a homeopathic medicinal product is 'any medicine prepared in accordance with a homeopathic manufacturing procedure described by a pharmacopoeia in official use or other officially recognised documents. A homeopathic

DOI: $10.21552 / \mathrm{ep} / \mathrm{r} / 2019 / 2 / 4$

* Alexander Natz is General Secretary of the European Confederation of Pharmaceutical Entrepreneurs (EUCOPE), Brussels. For Correspondence: <natz@eucope.org>. Gunther Herr is Member of EUCOPE's Executive Board. Robbert van Haselen is the Director of the World Integrated Medicine Forum. The analysis of the Eurasian Law was aligned with Sergey Klimenko, lawyer, a member of the Healthcare Expert Board of the Council of the Deration Committee on Social Policy, Moscow.

1 The Agreement entered into force on 12 February 2016. For an unofficial English translation see $<$ http://www

.eurasiancommission.org/en/act/texnreg/deptexreg/LS1/ Documents/AGREEMENT\%20MEDICINAL\%20PRODUCTS \%20WITHIN\%20THE\%20EURASIAN\%20ECONOMIC \%20UNION_eng_JL.pdf $>$ accessed 14 March 2019.

2 An overview can be found at <http://www.eurasiancommission .org/en/act/texnreg/deptexreg/LS1/Pages/default.aspx> accessed 14 March 2019; Zakharochkina et al, 'Uniform Rules for Registering Medicinal Products in the Eurasian Economic Union' (2018) J Pharm Sci \& Resm, 1045. 
medicine may contain a number of homeopathic preparations. ${ }^{3}$

\section{Homeopathic Tradition in Europe}

The principles of homeopathy were developed by the German physician and pharmacist Samuel Hahnemann (1755-1843). Whereas Hahnemann principally advocated the use of single remedies, already during his lifetime the use of combination remedies developed. $^{4}$

Nowadays, in the EU there is a stable demand for homeopathic medicinal products by patients. Around $29 \%$ of EU citizens use them for their health care. In the home countries of homeopathy, Germany and France, even up to $60 \%$ of the population uses homeopathic medicinal products. ${ }^{5}$ A recent survey of the European Homeopathic Medicinal Product Working Group (HMPWG) ${ }^{6}$ indicated that there are more than 12.000 registered homeopathic medicinal products in EU Member States, as well as more than 3.000 homeopathic medicinal products with a marketing authorisation. ${ }^{7}$

3 WHO, 'Safety Issues in the Preparation of Homeopathic Medicines' (2009) 26.

4 Cf Bettina Blessing, Pathways of Homeopathic Medicine (Springer 2011) 1 .

5 European Coalition on Homeopathic \& Anthroposophic Medicinal Products, 'A Thriving European Tradition' (2019) <https://www echamp.eu/our-sector> accessed 14 March 2019; Martin Dinges, 'Entwicklungen der Homöopathie seit 30 Jahren' (2012) ZKH 137. Specifically for Germany cf, Institut für Demoskopie Allensbach, 'Allensbacher Berichte' (2009) Nr 14 and Robert Jütte, 'Foreword' in Bettina Blessing, Pathways of Homeopathic Medicine (Springer 2011)

6 HMPWG is neither an institution of the EU nor an authority of an EU Member State. It is a working group of the Heads of Medicines Agencies ('HMA') dedicated to homeopathic medicinal products. It consists in particular of representatives of European national competent authorities.

7 Homeopathic Medicinal Products Working Group (HMPWG), 'Regulatory Status of Homeopathic Medicinal Products of Human Use in EU and EFTA Countries' (2016) 45-51.

8 Gomeopatia, 'The History of Homeopathy in Russia' (Gomeopatia 2019) <https://gomeopatia.org/index.php/istoriya-gomeopatii/74iz-istorii-gomeopatii-v-rossii > accessed 14 March 2019.

9 Valentine Tolochko et al, 'Сравнительный анализ ассортимента гомеопатических лекарственных средств на фармацевтическом рынке Украины, Российской федерации, Республик Беларусь и' (2018) 7 Georgian Medical News 8, 178 - 182. These figures reflect the status of 2018.

10 Committee on Youth, Family and Health of the German Bundestag, Bundestags-Drucksache 7/5091, 6 <http://dip21.bundestag .de/dip21/btd/07/050/0705091.pdf $>$ accessed 14 March 2019. For an overview of the development in German and European law Cf Wolfgang Voit, 'Anforderungen an die Verkehrsfähigkeit Homöopathischer Arzneimittel' (2017) PharmR 369, 370.

\section{Homeopathic Tradition in EAEU Territory}

Homeopathy was introduced to the Russian Empire by Dr. Adam in the first half of the 19th century. Dr. Adam was personally acquainted with Hahnemann and brought this new type of therapy to St. Petersburg in 1824. Dr. Schering and Dr. Bizhel, who translated the works of Hahnemann into Russian, were among the first to practice homeopathy in St. Petersburg. During the reign of Tsar Nicholas I (1825-1855) the first homeopathic pharmacies were opened in St. Petersburg, Moscow, Riga (1833) and in Kiev (1835). Since then, homeopathy has been officially recognised on the territory of the empire. ${ }^{8}$

Currently there appear to be around 468 registrations of homeopathic medicinal products in Russia. Belarus has 68 and Kazakhstan has 84 such registrations in their state registers. ${ }^{9}$ For single remedies such registrations may also cover a series of homeopathic medicinal products.

\section{Legislative Acknowledgement of Homeopathic Medicinal Products}

\section{Acknowledgement by the European Legislator: Concept of Method Neutrality and Scientific Pluralism}

In the EU, the European Commission initiated the establishment of regulatory requirements for homeopathic medicinal products in 1990. At that time, there already was an established regulatory system in Germany.

In Germany, the authorisation requirement for all medicinal products was introduced in 1976. Within this legislative procedure the rules for homeopathic medicinal products became part of the German drug law. With respect to homeopathic medicinal products, the competent Committee of the German Bundestag underlined that the legislator should remain neutral with respect to the different therapeutic approaches and avoid establishing one general binding 'state of scientific knowledge' for all medicinal products. ${ }^{10}$ The German Legislator was therefore guided by the political objective that scientific pluralism must be clearly reflected in the area of regulatory authorisations. As a result the regulatory system for homeopathic medicinal products in Germany is 
based on the concept of method neutrality and scientific pluralism. ${ }^{11}$

This approach was also adopted by the EU Legislator. The first Directive (92/73/EEC) with regard to homeopathic medicinal products emphasised that while quality and safety must be guaranteed, the patient must be permitted free access to medicinal products of his choice. ${ }^{12}$ In the reasoning of the European Commission's proposal for this Directive, reference was made to the legislative developments that took place in Germany in 1976 and to the above-mentioned principle of method neutrality as follows: 'It is not for the Commission to take sides for or against a particular style of medical practice. The aim should be rather, in the light of legislative experience in some of the Member States, to provide European consumers with safeguards about the quality and safety $[\ldots]^{\prime 13}{ }^{13}$ The Commission also referred to the importance of patient demand and emphasised that 'homeopathic remedies represent a small but not insignificant share of the pharmaceutical market $[\ldots . .]^{\prime 14}{ }^{14} \mathrm{Di}-$ rective 92/73/EEC was later transposed into the currently still valid Directive 2001/83/EC, ${ }^{15}$ but the fundamental positions have been maintained.

\section{Legislative Acknowledgement in EAEU Territory}

In EAEU territory, the first legislative mention of homeopathy took place in the first half of the $19^{\text {th }}$ century: The Resolution of the State Council 'Regulations on the Observation of Treatment by the Homeopathic System' was adopted in 1833 and included in the Code of Laws of the Russian Empire.

Despite homeopathic products being mentioned throughout the Soviet period and during the first years of the existence of the Russian Federation, the systematic legislative acknowledgment of homeopathy in the modern Russian legal environment was not initiated until 1995, when the Ministry of Healthcare of the Russian Federation issued Order No. 335 'On the use of the method of homeopathy in practical public health'. In Federal law No. 61-FZ 'On the circulation of medicines' dated 12 April 2010, homeopathic products were granted a solid, systematic body of rules, including their recognition as medicinal products and the introduction of requirements for their registration. Since 2010 homeopathic medicinal products are generally subject to the same reg- ulatory requirements as other medicinal products but certain specific provisions were introduced. ${ }^{16}$

Similar requirements to those of the Russian Federation were introduced in the laws of Belarus ${ }^{17}$ in 2006 and Kazakhstan ${ }^{18}$ in 2009.

\section{Union Law for Homeopathic Medicinal Products and its Legal Effect}

\section{European Directive 2001/83/EC and its Legal Effect}

The EU the regulatory requirements for homeopathic medicinal products for human use are contained in Directive 2001/83/EC as amended, in its Articles 14 to $16 .{ }^{19}$ In the context of homeopathic medicinal products the Advocate General at the CJEU stressed that the requirements of Articles 14 and 15 of Directive 2001/83/EC concerning simplified registration of homeopathic medicinal products are exhaustive and that Member States cannot impose stricter requirements, ie require applicants 'to provide documents

11 For details on the concept of scientific pluralism cf Heinz-Uwe Dettling, 'Wissenschaftlichkeit im Arzneimittelrecht - Zum Begriff des Jeweils Gesicherten Standes der Wissenschaftlichen Erkenntnisse - (Teil 3)' (2008) PharmR (2008) 418 - 419; Katrin Schumacher, Alternativmedizin (Springer 2016) 226.

12 Recitals of Directive 92/73/EEC of 22 September 1992 widening the scope of Directives 65/65/EEC and 75/319/ EEC on the approximation of provisions laid down by law, regulation or administrative action relating to medicinal products and laying down additional provisions on homeopathic medicinal products.

13 European Commission, Proposal for a Council Directive widening the scope of Directives 65/65/EEC and 5/319/EEC on the approximation of the laws of the Member States on medicinal products and laying down additional provisions on homeopathic medicinal products, COM (90) 72 final, Recital 4, 3.

14 ibid Recital 5, 3.

15 Directive 2001/83/EC of the European Parliament and of the Council of 6 November 2001 on the Community code relating to medicinal products for human use [2001] OJ L 311, 67.

16 For instance, special requirements are outlined in Articles 17 27.1(3), 30, 46 of the Federal law No 61-FZ 'On the circulation of medicines', these specifics are set out in detail in subordinate legislation - in particular, the Rules for expert examination of medicinal products to be conducted, approved by Order of the Ministry of Health No 558n establish special requirements for expert examination of homeopathic products (for instance it is not required to provide the results of pharmacokinetics and pharmacodynamics studies, etc)

17 Law of the Republic of Belarus N161-3 'On medicinal products'.

18 The Code of the Republic of Kazakhstan 'On the Health of the Population and Health Care System' No 193-IV.

19 (n 15). 
for which provision is not made in Article 15 of the directive.20

\section{EAEU Resolutions and their Legal Effect}

In EAEU law, the regulatory requirements for homeopathic medicinal products for human use can be found (amongst others) ${ }^{21}$ in the following documents (the 'EAEU Resolutions'):

- Rules of Authorisation and Assessment of Medicinal Products for Human Use" (alignment with n 31 and unofficial translation).

- the Requirements for the labelling and marking of medicinal products for human and veterinary use, approved by Resolution of the Council of the Eurasian Economic Commission No. 76) ('Resolution No. $76^{\prime}$ ).

Resolution No. 78 also provides for a period of transition from national to the common EAEU regulation as follows: Until 31 December 2020, at the discretion of the applicant, registration of the medicinal product can take place either in accordance with Resolution No. 78 or in accordance with the national legis-

20 Case C-444/03 Meta Fackler KG v Bundesrepublik Deutschland [2005] ECLI:EU:C:2005:288, Opinion of Advocate General Léger, paras 52, 53 and 8 .

21 Further regulatory requirements are scattered across the following documents: Council of the Eurasian Economic Commission, 'The Requirements for Instructions for Medicinal Products and General Information on Medicinal Products for Human Use' Resolution No 88; Council of the Eurasian Economic Commission, 'The Nomenclature of Dosage Forms' Resolution No 172; Council of the Eurasian Economic Commission, 'The Requirements for the Electronic Form of Applications and Registration Dossier Submitted during the Marketing Authorisation and Expert Examination of Medicinal Products for Human Use' Resolution No 79.

22 Art 6 (1) EAEU Treaty and Appendix 1 thereto.

23 C-84/06 Staat der Nederlanden v Antroposana [2007] ECLI:EU:C:2007:535, para 32; Verwaltungsgericht Köln, 7 K 2241/14, para $23 \mathrm{ff}$.

24 European Pharmacopoeia 9.1, 04/2017:1038, Homoeopathic Preparations, Dosage forms.

25 European Pharmacopoeia 9.1, 04/2017:1038, Homoeopathic Preparations, Potentisation.

26 According to Jütte and Riley there is a cut-off point of $\mathrm{C} 12$ or 24X/24D. See, Robert Jütte and David Riley, 'A Review of the Use and Role of Low Potencies in Homeopathy' (2005) Complementary Therapies in Medicine, 291, 292.

27 Cf ibid; Robbert van Haselen, 'To Which Extent Should Potency Choice in Homeopathy be 'Regulated': Has European Legislation Gone Too Far? (2005) Wiener Medizinische Wochenschrift, 479 480 . lation of the respective Member State. Medicinal products registered under the laws of the Member States need to be updated to the requirements of the EAEU Law by 31 December 2025.

The EAEU Resolutions are decisions of the Eurasian Economic Commission and are part of EAEU law. Due to the supranational nature of EAEU law they are subject to direct application in the territories of the Member States. ${ }^{22}$

\section{Union Definitions of Homeopathic Medicinal Product}

\section{EU Definition}

In the EU, homeopathic medicines are classified as medicinal products. ${ }^{23}$ For the entire EU, the term homeopathic medicinal product is furthermore defined by Article 1 (5) Directive 2001/83/EC as follows: 'Any medicinal product prepared from substances called homeopathic stocks in accordance with a homeopathic manufacturing procedure described by the European Pharmacopoeia or, in the absence thereof, by the pharmacopoeias currently used officially in the Member States. A homeopathic medicinal product may contain a number of principles'.

According to the definitions in the European Pharmacopoeia, the active substances used in a homeopathic medicinal product 'are considered to be 'dilutions or triturations of homeopathic stocks' or 'homeopathic stocks' (in case of a mother tincture or a glycerol macerate) $)^{24}$ Therefore active substances of homeopathic medicinal products can be the stock itself, in particular a mother tincture, or dilutions and triturations thereof. As described in the European Pharmacopoeia 'Dilutions and triturations are obtained from stocks by a process of potentisation [...]. The potentisation steps are usually [...] 1 part of the stock plus 9 parts of the vehicle; they may be designated as ' $\mathrm{D}$ ', 'DH' or ' $\mathrm{X}$ ' (decimal), [or] 1 part of the stock plus 99 parts of the vehicle; they may be designated ' $\mathrm{C}$ ' or ' $\mathrm{CH}$ ' (centesimal). The number of potentisation steps defines the degree of dilution; for example, 'D3', '3 $\mathrm{DH}^{\prime}$ or ' $3 \mathrm{X}$ ' means 3 decimal potentisation steps, and ' $\mathrm{C} 3$ ', ' $3 \mathrm{CH}$ ' or ' $3 \mathrm{C}$ ' means 3 centesimal potentisation steps. ${ }^{25}$

Whereas in high dilutions the presence of molecular traces of the original substances is unlikely $y^{26}$ this is not the case when lower dilutions are used. ${ }^{27}$ 
However, as far as the term 'homeopathic medicinal product' is concerned, the distinctions between high and low dilutions are not relevant from a legal perspective, since the definition in Article 1 (5) Directive $2001 / 83 / E C$ is - on purpose - strongly related to the manufacturing process. ${ }^{28}$

This definition comprises the various levels of (low to high) dilutions; it is not limited to specific forms/schools of homeotherapy and does not exclude any dosage form.

According to this definition, the preparation of the medicinal product must follow the manufacturing procedure described by the recognised official European pharmacopoeias. Recognised official pharmacopoeias are the European Pharmacopoeia and in case a manufacturing procedure has so far not been transferred into the European Pharmacopoeia also the German Homeopathic Pharmacopoeia and the French Pharmacopoeia, but not the Indian Homeopathic Pharmacopoeia or the Homeopathic Pharmacopoeia of the United States (HPUS). The definition does, however, not require that the substances called homeopathic stocks are themselves also monographed in these recognised pharmacopoeias.

The second sentence of the definition in Article 1 (5) Directive 2001/83/EC referring to the 'principles' (active substances) of a homeopathic medicinal product, is of declaratory character only. Clarification is made that a homeopathic medicinal product may also contain multiple active substances, thus this definition specifically includes what are known as homeopathic combination products which contain several active substances. ${ }^{29}$ This clarification is also reiterated in the European Pharmacopoeia. ${ }^{30}$

The definition of a 'homeopathic medicinal product' has turned out to be sufficiently clear and has hardly caused legal disputes in the EU so far.

\section{EAEU Definition}

For the entire EAEU, the term homeopathic medicinal product is defined in Chapter II (Definitions), Section 19 Resolution No. 78. ${ }^{31}$ Accordingly, homeopathic medicinal product is a 'a medicinal product prepared from homeopathic stocks in accordance with a homeopathic manufacturing procedure described by the Union Pharmacopoeia or, in the absence thereof, by homeopathic pharmacopoeias'.
This EAEU definition is very similar to the one provided for in the EU. Solely this definition does insofar diverging from Directive 2001/83/EC - not contain a second sentence clarifying that a homeopathic medicinal product may also contain several active substances. However, this clarification is already inherent to the first sentence of the definition ('prepared from homeopathic stocks') and to the general definition of a medicinal product in Article 1 (1) of the Agreement as 'any product that consists of or contains a substance or combination of substances [...].'

The establishment of the EAEU Pharmacopoeia, including the related provisions on homeopathic medicinal products, is still in an early phase. Therefore, the definition also refers to other homeopathic pharmacopoeias. It can be concluded from Appendix 1 Section 14.1 Resolution No. $78^{32}$ that such other pharmacopoeias are in particular those of the EAEU Member States, the European Pharmacopoeia and the German Homeopathic and French Pharmacopoeias. The wording of the definition itself is, however, not explicitly limited to these pharmacopoeias. Consequently, it may also allow reference to further pharmacopoeias as well. As in the EU, the homeopathic manufacturing procedure needs to be in accordance with the pharmacopoeia, and like in the EU it is not required that the homeopathic stock(s) contained in the medicinal product are themselves also monographed in a pharmacopoeia.

\section{Comparison}

Both legal orders (of the EU and EAEU) provide a very similar, clear and practical definition of a homeopathic medicinal product. These definitions are in

28 In 1990 the European Commission stressed in its Proposal for a Council Directive related to homeopathic medicinal products ( $\mathrm{n}$ 13): 'Homeopathic medicinal products are defined primarily by the way they are made up [...]. This 'objective' method of definition, which is the one adopted in the German legislation, has the advantage of not taking sides in the argument over the philosophy or rational basis of homeopathy $[\ldots]^{\prime}$.

29 Christiane Kirchner et al, 'Unbedenklichkeit und Qualität Homöopathischer Arzneimittel' (2010) A \& R, 108, 109; Regarding homeopathic combination products cf Blessing (n 4).

30 European Pharmacopoeia 9.1, 04/2017:1038, Homoeopathic Preparations, Dosage forms.

31 Council of the Eurasian Economic Commission, 'Rules of Authorisation and Assessment of Medicinal Products for Human Use' Resolution No 78.

32 ibid Appendix 1. 
line with the definition used by $\mathrm{WHO}^{33}$ and by many other countries. ${ }^{34}$ Both definitions are manufacturing related, classify homeopathic medicines as medicinal products, include combination products and neither exclude any level of dilution nor dosage form nor specific forms or schools of homeotherapy. ${ }^{35}$ Both definitions require that the manufacturing process follows the manufacturing procedure of the relevant pharmacopoeia but the definition does not require that the homeopathic stocks contained in the homeopathic medicinal product are themselves monographed in one of the pharmacopoeias.

As further explained below, the classification as medicinal products make homeopathic medicines subject to an authorisation/registration requirement in both legal regimes.

\section{General Authorisation/Registration Requirement}

\section{EU}

According to Article 6 (1) Directive 2001/83/EC the placing on the market of medicinal products in the entire EU requires a prior authorisation either in accordance with Directive 2001/83/EC or Regulation (EC) No 726/2004. For homeopathic medicinal products such authorisation may either be granted in the marketing authorisation procedure as referred to in Article 16 Directive 2001/83/EC, or - for homeopathic medicinal products without therapeutic indications - in the simplified registration procedure pursuant to Articles 14 and 15 Directive 2001/83/EC. Without a prior marketing authorisation or registration issued by the competent authority homeopathic medicinal products may not be placed on the market in the entire EU.

\section{EAEU}

Similarly, according to Article 8 (1) of the Agreement, the marketing of medicinal products within the

33 WHO (n 3).

34 For example in Canada, Colombia, Mexico, Switzerland, Ukraine.

35 For the term 'homeotherapy' cf WHO, 'Safety Issues in the Preparation of Homeopathic Medicines' (2009) $27<$ https://www.who .int/medicines/areas/traditional/Homeopathy.pdf> accessed 14 March 2019
EAEU shall be allowed only after a registration was granted in accordance with the procedure established by the Commission. Article 7 (1) of the Agreement provides that the Member States of the EAEU shall grant a registration and carry out the assessment of medicinal products intended for circulation in the common market in accordance with the Rules established in Resolution No. 78. Resolution No. 78 establishes common requirements for the procedure of registration for medicinal products in the EAEU. For homeopathic medicinal products, the registration application can also be based on a simplified dossier.

\section{Comparison}

Due to their classification as medicinal products, homeopathic medicinal products are subject to a registration/authorisation requirement in both the EU and the EAEU. This means that homeopathic medicinal products can only be placed on the market after having been checked and registered/authorised by the competent authority.

\section{Specific Provisions for Homeopathic Medicinal Products Authorised under National Law}

Both Union laws to a certain extent account for medicinal products that have already been nationally registered or authorised before the new Union law coming into force.

\section{Nationally Authorised or Registered Homeopathic Medicinal Products in the EU}

When homeopathic medicinal products were included into EU law on medicinal products in 1992, Article 10 (2) Directive 92/73/EEC required that applications for registrations or marketing authorisations for homeopathic medicinal products lodged after 31 December 1993 comply with this Directive. This rule was transferred to Directive 2001/83/EC. According to Article 13 (1) Directive 2001/83/EC 'Member States shall ensure that homeopathic medicinal products manufactured and placed on the market within the 
Community are registered or authorised in accordance with Articles 14, 15 and 16, except where such medicinal products are covered by a registration or authorisation granted in accordance with national legislation on or before 31 December 1993'. Vice versa Member States may maintain own national law for homeopathic medicinal products authorised or registered nationally until 31.12.1993. Some Member State have made use of the latter possibility. ${ }^{36}$

\section{Nationally Authorised or Registered Medicinal Products in the EAEU}

In contrast to EU law, EAEU law does not contain specific transitory provisions for homeopathic medicinal products authorised or registered nationally. EAEU law, however, contains in Sections 170 to 183 Resolution No. 78 general requirements for updating medicinal products authorised or registered nationally before 31.12.2020. According to Section 170 Resolution No. 78 medicinal products authorised nationally in the Member States before the Agreement came into effect or using national procedures before 31 December 2020 need to be brought into compliance with the requirements of the Union until 31 December 2025 . Where a medicinal product has, however, been authorised nationally in more than one Member State before 31 December 2020, Section 175 Resolution No. 78 contains an exception as regards to Modules 4 and 5. It stipulates that all 'available data on non-clinical and clinical studies performed before the Agreement came into effect [...] shall be submitted in this case in Modules 4 and 5 of the marketing authorisation dossier in the form of appropriate reports without mandatorily bringing them into compliance with the requirements of the Union'. A similar provision is contained in Article 182 in case a national marketing authorisation shall be recognised via the mutual recognition procedure in other Member States.

\section{Comparison}

EAEU-law does, in contrast to EU law, not contain specific transitory provisions for homeopathic medicinal products. The general transitory provisions, under certain circumstances as laid down in Sections 175 and 182 Resolution No. 78, however, allow appli- cants to compile Modules 4 and 5 in the form of appropriate reports summarizing the existing available data. This also applies for homeopathic medicinal products.

\section{Simplified Procedures and their Requirements}

\section{Simplified Registration Procedure in the EU}

In the EU in the interest of safety, quality and product availability a simplified registration procedure became part of EU law in 1992.

\section{a. The Core Requirements}

In the EU pursuant to Article 14 (1) Directive 2001/83/EC, homeopathic medicinal products are eligible for the simplified registration procedure if the following three requirements are met:

- they are administered orally or externally,

- no therapeutic indication appears on the labelling of the medicinal product or in any information relating thereto and

- there is a sufficient degree of dilution to guarantee the safety of the medicinal product; in particular, the medicinal product may not contain either more than one part per 10,000 of the mother tincture or more than $1 / 100$ th of the smallest dose used in allopathy with regard to active substances whose presence in an allopathic medicinal product results in the obligation to submit a doctor's prescription.

As therapeutic indications cannot appear on the labelling in such a case, Article 14 (2) Directive 2001/83/EC clarifies that proof of therapeutic efficacy is not required in the simplified registration procedure. $^{37}$

Furthermore, Article 15 Directive 2001/83/EC lists the quality documents to be provided by the applicant and requires the applicant to justify the home-

\footnotetext{
36 HMPWG (n 7) 14, 15.

37 Voit (n 10) 372.
} 
opathic use of the homeopathic stock(s) contained in the product on the basis of adequate bibliography. For the justification of homeopathic use, reference can be made either to a substance monograph in an officially used pharmacopoeia, to Materia Medica, or the results of homeopathic provings or other bibliographic data, such as literature references. ${ }^{38}$ The possibility to make reference to literature is important because the European Pharmacopoeia does so far not contain many substance monographs of homeopathic stocks and the German and French homeopathic pharmacopoeias also only contain a limited, non-exhaustive list of monographed stocks.

The required quality and safety documentation for simplified registration is further specified in Annex 1 Part III. 3. Directive 2001/83/EC. ${ }^{39}$ By way of the requirements in Articles 14 and 15 and the related provisions in Annex 1 Directive 2001/83/EC quality and safety of homeopathic medicinal products is ensured in the same manner as for any other medicinal product. $^{40}$

\section{b. Interpretation of Core Requirements}

These core requirements had already been part of the first European directive on homeopathic medicinal products in $1992 .{ }^{41}$ Since that time the interpretation and application within the different Member States has, however, to a certain extent been rather incoherent. For example, it needed to be made clear by the CJEU ${ }^{42}$ and also by the European Commission $^{43}$ that Articles 14 and 15 Directive 2001/83/EC contain an exhaustive list of requirements for the simplified registration procedure and that the EU

38 HMPWG, 'Points to Consider on the Justification of Homeopathic Use of the Stock' (2012) <http://www.hma.eu/380.html> accessed 14 March 2019.

39 HMPWG developed more detailed regulatory guidance documents on quality and safety. See <http://www.hma.eu/380.html> accessed 14 March 2019. Concerning the requirements for quality in Germany of Kirchner et al (n 29) $113 \mathrm{f}$.

40 Cf Voit (n 10) 371 f; Schumacher (n 11) 142 ff; Kirchner et al (n 29) 111.

41 Directive 92/73/EEC (n 12).

42 Opinion of Advocate General Léger (n 20).

43 European Commission Letter to Heads of Medicines Agencies (HMA), Ref Ares(2011)210866.

44 Communication from the Commission to the Council and the European Parliament, COM(2008) 584 final, 6.

45 European Commission Letter, Ref Ares(2010)659356.
Member States are not allowed to impose additional or stricter requirements. Additionally, the CJEU and/or the Commission provided the following guidance:

\section{i. 'Administered Orally or Externally'}

Concerning the condition 'administered orally or externally', the question arose whether the simplified registration procedure is also open for pharmaceutical forms such as nasal, eye or ear drops and suppositories.

In Directive 2001/83/EC, the terms 'oral' and 'external' are not only used for homeopathic medicinal products but - in Article 16a (1c) - also for traditional herbal medicinal products.

In a publication concerning traditional herbal medicinal products ${ }^{44}$ the European Commission referred to the term 'external use' and clarified the following: ' $[. .$.$] the term 'external' means mainly appli-$ cation on the skin, but includes topical, oral, nasal, rectal, vaginal, ocular or auricular use'. The European Commission underlined that in order to maintain consistency, the same interpretation applies to homeopathic medicinal products under the simplified registration procedure. ${ }^{45}$

As a result the term 'administered orally or externally' in Article 14 (1) Directive 2001/83/EC is to be interpreted that it includes oral, topical, nasal, rectal, vaginal, ocular or auricular use, but not parenteral use.

\section{ii. 'Not More than one Part per 10,000 of the Mother \\ Tincture in the Product'}

Sometimes national competent authorities of EU Member States question whether the Directive's '1:10,000' requirement excludes homeopathic medicinal products with lower homeopathic potencies than $\mathrm{D}_{4}$ or $\mathrm{C} 2$ from the simplified registration procedure. As the excerpt from a product composition in the table below shows, the actual concentration of the mother tincture in the product is very often different from the homeopathic potency.

This example illustrates that a $\mathrm{D}_{3}$ or even D2 potency may end up with an actual concentration of at least 1:10,000 and is then also eligible for simplified registration.

In the clear wording of Article 14 (1) Directive 2001/83/EC no reference is made to minimum homeopathic dilutions such as 'D4' or 'C2'. Instead the provision says that 'the medicinal product may not con- 
Example illustrating 1 per 10,000 requirement

\begin{tabular}{|l|l|l|l|l|}
\hline \multicolumn{5}{|l|}{ Tablets containing $300 \mathrm{mg}$} \\
\hline $\begin{array}{l}\text { Substances } \\
\text { (excerpt) }\end{array}$ & $\begin{array}{l}\text { HAB } \\
\text { (Ph. Eur.) }\end{array}$ & $\begin{array}{l}\text { Amo } \\
\text { unt }\end{array}$ & $\begin{array}{l}\text { Po- } \\
\text { tency }\end{array}$ & $\begin{array}{l}\text { Actual Con- } \\
\text { centration }\end{array}$ \\
\hline $\begin{array}{l}\text { Myristica fra- } \\
\text { grans }\end{array}$ & $4 \mathrm{a}(1.1 .8)$ & $\begin{array}{l}30.0 \\
\mathrm{mg}\end{array}$ & $\mathrm{D} 4$ & $1: 100,000$ \\
\hline $\begin{array}{l}\text { Lycopodium } \\
\text { clavatum }\end{array}$ & $4 \mathrm{a}(1.1 .8)$ & $\begin{array}{l}3.0 \\
\mathrm{mg}\end{array}$ & $\mathrm{D} 2$ & $1: 10,000$ \\
\hline $\begin{array}{l}\text { Cinchona pu- } \\
\text { bescens }\end{array}$ & $4 \mathrm{a}(1.1 .8)$ & $\begin{array}{l}3.0 \\
\mathrm{mg}\end{array}$ & $\mathrm{D} 3$ & $1: 100,000$ \\
\hline
\end{tabular}

tain $[. .$.$] more than one part per 10000$ of the mother tincture'. As the European Commission explicitly confirmed $^{46}$ the 1:10,00o requirement is solely linked to the actual (final) concentration of the mother tincture in the product, but not to the homeopathic potency of $\mathrm{D}_{4}$ or $\mathrm{C} 2$.

\section{iii. 'Homeopathic Use' of the Stock(s)}

Concerning the term 'homeopathic use' there have been discussions whether in addition to the justification of the 'homeopathic use' of each individual stock contained in the medicinal product further justification would be required related to eg the homeopathic use of the combination of different homeopathic stocks in a homeopathic combination product or the homeopathic use of the application mode of the product, eg for topical use.

The wording of Article 15 Directive 2001/83/EC requires a 'dossier describing how the homeopathic stock or stocks is/are obtained and controlled, and justifying its/their homeopathic use, on the basis of an adequate bibliography'. According to this wording the homeopathic use of the stock or stocks contained in the homeopathic medicinal product needs to be justified. There is, however, no further requirement to additionally justify the homeopathic use of the combination or of the route of administration. ${ }^{47}$ This was also made clear by the CJEU in its Judgment of 12 May $2005^{48}$ in the context of a combination product where the Court held that 'It is clear from Article 15 of Directive 2001/83, which lists the documents which must be included in the application for registration by special simplified procedure for a homeopathic medicinal product, that only the home- opathic stock or stocks from which that combination is derived must be well-known. Thus, the first indent of that provision states that the scientific name or other name given in a pharmacopoeia of the homeopathic stock or stocks is to be stated, together with a statement of the various routes of administration, pharmaceutical forms and degree of dilution to be registered, while the second indent of that provision requires a dossier to be lodged describing how the homeopathic stock or stocks is/are obtained and controlled, and justifying its/their homeopathic nature, on the basis of an adequate bibliography. However, a bibliography showing that the effects of the homeopathic medicinal product itself have been identified is not required.'

\section{Simplified Procedure in the EAEU}

In the EAEU law Appendix 1 Section 14.4 Resolution No. 78 contains specific rules for homeopathic medicinal products to be eligible for providing a simplified dossier. The three core requirements to be eligible for simplified registration procedure are almost identical to the ones in EU law, namely:

- the medicinal product is administered orally or externally, or locally, or in the form of inhalation;

- no specific therapeutic indication appears on the packaging, summary of product characteristics (SmPC) or medication guide of the medicinal product;

- there is a sufficient degree of dilution to guarantee the safety of the medicinal product; in particular, the medicinal product may not contain either more than one part per 10,000 of the mother tincture or more than $1 / 100$ th of the smallest dose used in allopathy with regard to active substances whose presence in an allopathic medicinal product results in the obligation to submit a doctor's prescription.

46 European Commission Letter, ENTR/F2/MT/PTT/jr D (2009) 3170.

47 Kirchner et al (n 29) 111.

48 Case C-444/03 Meta Fackler KG v Bundesrepublik Deutschland [2005] ECLI:EU:C:2005:288, para 20. In this proceeding the Opinion of the Advocate General (n 20) stressed that the requirements of Arts 14 and 15 Directive are exhaustive (paras 52,53) and a Member States cannot require applicants 'to provide documents for which provision is not made in Article 15 of the directive' (para 81). 
Also corresponding to EU law, as homeopathic medicinal products under the simplified procedure cannot refer to any specific therapeutic indications, Appendix 1 Section 14.4 Resolution No. 78 clarifies that proof of therapeutic efficacy is not required for simplified registration.

Just as in EU law, Appendix 1 Section 14.4 Resolution No. 78 lists the quality documents to be provided by the applicant and requires the applicant to justify the homeopathic use of the homeopathic stock(s) contained in the product on the basis of adequate bibliography. Like in EU law, the wording of Resolution No. 78 implies that the homeopathic use of the homeopathic stock(s) does not necessarily need to be justified by reference to substance monographs in a pharmacopoeia. Instead other homeopathic literature may be used as well. This is important as neither the pharmacopoeia of the EAEU nor the pharmacopoeias of the EAEU Member States currently contain any substance monographs of homeopathic stocks. Also, other pharmacopoeias, if at all, contain a limited but not exclusive list of homeopathic stocks.

\section{Comparison}

The EU and the EAEU legal systems introduced certain simplified registration procedures to improve access to homeopathic medicinal products, while ensuring their safety and good quality. There are no substantial differences between these procedures in both legal systems which both guarantee quality and safety of the registered homeopathic medicinal products. The legal requirements for simplified registration are therefore almost the same for 33 individual countries. From a legal perspective this high level of coherence should allow for the use of the same or very similar regulatory documentation for simplified registration in both unions.

The past regulatory practice within the EU shows: From the legal perspective the simplified registration procedure is a very helpful tool for market access of homeopathic medicinal products. ${ }^{49}$ Harmonised requirements in EU law are, however, not always co-

49 There are more than 12.000 registered homeopathic medicinal products in EU Member States. See, HMPWG (n 7) 45-47. herently interpreted by the different EU Member States. Against this background it is desirable that the core requirements described above, in particular the terms oral or external use, 1:10,000 and homeopathic use of the stock(s) are in the future more coherently applied, also in closer adherence to the guidance already provided by the CJEU and European Commission.

Similarly, it is desirable that from the onset the legal requirements of the registration procedure for the simplified dossier are applied coherently by the EAEU Member States and that the experiences obtained with the almost identical requirements in the EU are taken into account.

Since both legal regimes established almost identical legal requirements, there is even an opportunity that a coherent standard is applied within the 33 countries of both the EU and the EAEU. This would be an important contribution to enhanced availability of homeopathic medicinal products in both Unions.

\section{IX. (Non-Simplified) Authorisation/Registration Procedure}

\section{Marketing Authorisation in the EU}

In the EU all homeopathic medicinal products which are not eligible for simplified registration must obtain a marketing authorisation according to Article 16 (1) Directive 2001/83/EC. Homeopathic medicinal products for parenteral use, with dilutions lower than one part per 10,000 of the mother tincture and/or with therapeutic indications, do not fulfill the requirements for simplified registrations and therefore need a marketing authorisation. Article 16 (1) Directive 2001/83/EC clarifies that homeopathic medicinal products may be authorised and labelled following the provisions applicable for other medicinal products. According to Article 16 (2) Directive 2001/83/EC a Member State may introduce or retain in its territory specific rules for the Module 4 and Module 5 requirements 'in accordance with the principles and characteristics of homeopathy as practiced in that Member State'.

As far as the quality requirements (Module 3) are concerned, the specific provisions of Annex 1 Part III. 3. Directive 2001/83/EC apply in all marketing au- 
thorisation procedures. Marketing authorisation can be obtained via different procedures:

\section{a. 'Mixed Marketing Authorisations'}

If the application is based on Article 8 Directive 2001/83/EC the results of pharmaceutical tests, preclinical tests and clinical trials need to be submitted..$^{50}$ In Annex 1 Part I Directive 2001/83/EC the further details related to this documentation are described which are specified in Module 3 (quality part of the Common Technical Document including the specific provisions in Annex 1 Part III. 3. Directive 2001/83/EC), in Module 4 (non-clinical part of the Common Technical Document) and in Module 5 (clinical part of the Common Technical Dossier). Within this procedure the possibility to provide a combination of reports of non-clinical and/or clinical reports and of bibliographic references as a mixed marketing authorisation application according to Annex 1 Part II 7. Directive 2001/83/EC is one regulatory option for homeopathic medicinal products.

\section{b. 'Well-Established Use'}

Another option is a well-established use application. According to Article 10a Directive 2001/83/EC as further outlined in Annex 1 Part II 1. Directive 2001/83/EC an application can also be based on appropriate scientific literature if the active substances of the medicinal product have been in well-established medicinal use within the European Union for at least ten years.

\section{c. National Rules based on Article 16 (2) Directive 2001/83/EC}

Additionally, Article 16 (2) Directive 2001/83/EC gives all EU Member States the possibility to introduce or retain in their territory specific rules for the pre-clinical tests (Module 4) and clinical trials (Module 5), but not for the pharmaceutical tests (Module 3) of homeopathic medicinal products. In the EU legislator's opinion, the 'Member States which have a homeopathic tradition should be able to apply particular rules. ${ }^{51}$

A recent Homeopathic Medicinal Product Working Group (HMPWG) report indicates that national rules are currently available in 10 EU Member States, including Germany, ${ }^{52}$ France, Austria and Belgium.
Altogether more than 2,300 national marketing authorisations for homeopathic medicinal products have been granted so far. ${ }^{53}$

Most of these Member States used this possibility for national rules for homeopathic medicinal products with a therapeutic indication. Article 16 (2) does, however, also enable national rules for homeopathic medicinal products (with or without therapeutic indication) for parenteral use and/or for lower dilutions than 1 per 10,000. As far as Member States have made use of Article 16 (2) Directive 2001/83/EC the requirements related to the non-clinical (Module 4) and clinical part (Module 5) of the dossier are to be specified in the national laws of the individual Member States. The national rules concerning Module 4 in the relevant EU Member States are generally the same as in the simplified registration procedure. The national rules for Module 5 are derived from the principles and characteristics of homeopathy as practiced in the respective Member State and there are therefore differences from country to country. Due to these national differences, Article 39 of Directive 2001/83/EC clarifies that the mutual recognition and decentralized procedures cannot be applied to homeopathic medicinal products that are registered based on Article 16 (2) Directive 2001/83/EC.

\section{d. Justification of the Stocks' Homeopathic Character}

In the EU, as for simplified registrations, also for homeopathic medicinal products subject to marketing authorisation, it is not required that the homeopathic stocks used in the manufacturing process are necessarily monographed in official European pharmacopoeias. Instead, it is sufficient that the homeopathic character of the stocks used in the medicinal product can be derived from other bibliography. ${ }^{54}$

50 Art 8 (3) (i) Directive 2001/83/EC.

51 Preamble of Directive 92/73/EEC (n 12).

52 In Germany there are 1.250 authorised homeopathic medicinal products (status as of May 2019).

53 There are more than 2.300 homeopathic medicinal products authorized based on Article 16 (2) Directive 2001/83/EC in EU Member States. See, HMPWG (n 7) 50, 51.

54 The EU requirements for marketing authorisation according to Article 16 Directive 2001/83/EC do, differently from those for simplified registration, not explicitly require justifying the stocks' homeopathic use. The demonstration of the stocks' homeopathic character is, however, already inherent to the definition of a homeopathic medicinal product. 


\section{2. (Non-Simplified) Registration in the EAEU}

EAEU law also contains specific provisions related to the regulatory dossier for (non-simplified) registration in Appendix 1 Sections 14.1 - 14.3 Resolution No. 78. There are, however, no provisions excluding homeopathic medicinal products from other regulatory procedures available for medicinal products un der EAEU law. Consequently, the other procedures are also open for homeopathic medicinal products if the requirements are met.

\section{a. 'Well-Established Use'}

Like in the EU, for certain homeopathic medicinal products a regulatory option may be the 'well-established use' procedure. Well-established use of medicinal products is defined in Chapter II (Definitions), Section 19 Resolution No. 78 and requires amongst others a well-established medicinal use for at least ten years in at least 3 Member States. The requirements for registration are furthermore provided in Appendix 1 Section 8 Resolution No. 78. Overall, the requirements for a well-established use registration in the EAEU are again similar to those in the EU.

\section{b. Specific Provisions for (Non-Simplified) Registration of Homeopathic Medicinal Products}

Similar to EU law, there are also specific provisions for non-simplified registration/authorisation in EAEU law if a homeopathic medicinal product is not eligible for simplified registration.

Whereas EU law also allows Member States to maintain or introduce national rules for the non-clinical and clinical data (Modules 4 and 5), in the EAEU, also the specific requirements for Modules 4 and 5 are laid down in EAEU law (Appendix 1 Sections 14.1 -14.3 Resolution No. 78).

Appendix 1 Section 14.1 Resolution No. 78 provides for the quality requirements (Module 3) very similarly to Annex 1 Part III. 3. Directive 2001/83/EC. In this Section reference is made twice to 'the Phar-

55 In the Public consultation on the Draft Resolution 'Regulations for Registration and Expert Assessment of Medicinal Products' these difficulties with related proposals were addressed by EUCOPE's statement submitted on 27 August 2015. macopoeia of the Eurasian Economic Union (where available) or a homeopathic pharmacopoeia of Member States or the Homeopathic pharmacopoeia of Germany, the Pharmacopoeia of France and the European Pharmacopoeia'.

Both the requirements for Modules 4 and 5 addressed in Appendix 1 Section 14.2 and 14.3 Resolution No. 78 start with a general statement and then differentiate whether the product at stake is a 'new homeopathic medicinal product' or not.

\section{i. General Statements Related to Modules 4 and 5}

According to the general statements in both Sections 'any missing data shall be justified'. As far as Module 4 is concerned justification can be provided 'why demonstration of an acceptable level of safety can be supported although some studies are lacking'. As far as Module 5 is concerned 'an acceptable efficacy and safety profile in the absence of particular studies' needs to be demonstrated. These introductory sentences clarify that bibliography (literature) may replace the results of non-clinical or clinical data.

\section{ii. New Homeopathic Medicinal Products and Related Distinctions (Modules 4 and 5)}

However, according to Appendix 1 Section 14.2 Resolution No. 78 (Module 4), for 'new homeopathic medicinal products (mother tinctures, triturations or other ingredients) not described in pharmacopoeias and monographs non-clinical toxicity data, dose response data and subsequent clinical data are essential'.

According to Appendix 1 Section 14.3 Resolution No. 78 (Module 5) for 'new homeopathic medicinal products (mother tinctures, triturations or other ingredients) not described in pharmacopoeias and monographs clinical data and dose response data are essential', whereas 'for homeopathic medicinal products being in use for many years and described in pharmacopoeias the scientific review of the efficacy and safety of the homeopathic medicinal product in the claimed indication shall be provided'.

\section{iii. Appendix 1: Questions and (Potenial) Solutions}

In the interpretation of the terms and requirements in Appendix 1 Section 14.2 and 14.3 Resolution No. 78 in particular the following questions arise. ${ }^{55}$

- What is a 'new' homeopathic medicinal product?

- What is a homeopathic medicinal product 'being in use for many years' and described in 'pharma- 
copoeias'? Why is here the term 'pharmacopoeias' not used in conjunction with 'and monographs'?

- When are homeopathic medicinal products (mother tinctures, triturations or other ingredients), or in other words when are ingredients of homeopathic medicinal products, described in 'pharmacopoeias and monographs'?

The answers to these questions are essential for applicants: Not only in the case of applications for new registrations but in particular also when bringing the homeopathic medicinal products already registered under the national laws of the Member States into compliance with EAEU law until end of 2025.

Due to the importance of and the difficulties associated with these questions the interpretation of Appendix 1 Section 14.2 and 14.3 Resolution No. 78 requires careful consideration. The following considerations and proposals may be supportive:

- The word 'new' in the term 'new homeopathic medicinal product' implies that at least all the homeopathic medicinal products registered under national law in the EAEU Member States need to be considered as existing products and not as 'new' ones. The fact that already nationally authorised medicinal products cannot be considered as new ones is also confirmed by the transitory provision in Section 170 Resolution No. 78. This provision requires an update for medicinal products authorised in the Member States before the Agreement came into force on 12 February 2016 or using national procedures before 31 December 2020.

- In Appendix 1 Section 14.3 Resolution No. 78 the term homeopathic medicinal product 'being in use for many years' is introduced. This term can hardly be considered another expression of 'well-establisheuse' as defined in Section 19 Resolution No. 78. Being in use for many years is according to its wording solely related to the duration of the product's use. It does not contain limitations regarding its specific medicinal use in a specific number of EAEU Member States. Against this background, the authors' are of the opinion that the required period of use cannot exceed the one required for well-established use. As a result, at least 10 years of use appears to be sufficient.

- In Appendix 1 Sections 14.2 (Module 4) and 14.3 (Module 5) Resolution No. 78 the words 'pharmacopoeias and monographs' are also not further specified. Firstly, the common principle that generally many homeopathic stocks with justified homeopathic use are not substance monographed in specific pharmacopoeias should be duly taken into account. Secondly, in Appendix 1 Section 14.2 (Module 4) and Section 14.3 (Module 5) Resolution No. 78 , the reference to pharmacopoeias or monographs is not further restricted. In contrast to this, Appendix 1 Section 14.1 (Module 3) Resolution No. 78 specifically refers to the official Eurasian and European pharmacopoeias. Contrary to this, the term 'pharmacopoeias' as used in Appendix 1 Sections 14.2 (Module 4) and 14.3 (Module 5) Resolution No. 78 is broader, also allowing references to other pharmacopoeias, such as for example the Brazilian and Indian pharmacopoeias as well as the Homeopathic Pharmacopoeia of the United States (HPUS).

As far as the term 'monographs' is concerned, the wording of Appendix 1 Sections 14.2 (Module 4) and 14.3 (Module 5) Resolution No. 78 also does not contain a requirement that the monographs need to be part of a pharmacopoeia. Consequently, reference can also be made to monographs contained in Materia Medica, the results of homeopathic provings, or monographs of Commission $\mathrm{D}$ or other bibliographic data. ${ }^{56}$ This is important, because, as explained above, the homeopathic use of a substance cannot only be justified with reference to substance monographs in pharmacopoeias but also with reference to other data.

- Whereas in the context of 'new homeopathic medicinal products' explicit reference is made twice to 'pharmacopoeias and monographs', in the context of 'homeopathic medicinal products being in use for many years' it appears that the inclusion of the word 'monograph' was accidentally forgotten in the sentence related to homeopathic medicinal products 'being in use for many years'. This gap can be closed by also allowing the applicant to refer to 'monographs' when applying for registration of homeopathic medicinal products 'being in use for many years'.

An interpretation in line with these proposals will allow applicants which need to bring national registrations into compliance with EAEU law until end of

56 This is also the approach in the EU, cf HMPWG (n 38). 
Overview of non-cinical and clinical requirements

\begin{tabular}{|l|l|l|}
\hline Categories & Module 4 (Non-Clinical) & Module 5 (Clinical) \\
\hline $\begin{array}{l}\text { New homeopathic medicinal products } \\
\text { with ingredient(s) neither described } \\
\text { in pharmacopoeias nor monographs }\end{array}$ & $\begin{array}{l}\text { Non-clinical toxicity data, dose response } \\
\text { data and subsequent clinical data }\end{array}$ & Clinical data and dose response data \\
\hline $\begin{array}{l}\text { Homeopathic medicinal products in } \\
\text { use for many years with ingredient(s) } \\
\text { described in pharmacopoeias or } \\
\text { monographs }\end{array}$ & $\begin{array}{l}\text { [Not addressed in Module 4 but cf. Mod- } \\
\text { ule 5: Scientific review of the safety in } \\
\text { the claimed indication }\end{array}$ & $\begin{array}{l}\text { Scientific review of the efficacy and } \\
\text { safety in the claimed indication }\end{array}$ \\
\hline $\begin{array}{l}\text { Other homeopathic medicinal prod- } \\
\text { ucts }\end{array}$ & $\begin{array}{l}\text { [Not addressed, therefore:] Any missing } \\
\text { data shall be justified, eg justification } \\
\text { why acceptable level of safety can be } \\
\text { supported although some studies are } \\
\text { lacking }\end{array}$ & $\begin{array}{l}\text { [Not addressed, therefore:] Any missing } \\
\text { data shall be justified, eg justification of } \\
\text { acceptable efficacy and safety profile in } \\
\text { the absence of particular studies }\end{array}$ \\
\hline
\end{tabular}

2025 to demonstrate safety and efficacy also via bibliography. It would not be appropriate to require amongst others dose response data as essential for these already existing and nationally registered homeopathic medicinal products because due to the dilution of these products such data cannot, or hardly, be generated.

A narrower interpretation than the proposed one of the term pharmacopoeias and monographs would neglect the fact that the homeopathic character of a lot of substances used in already registered and authorised homeopathic medicinal products inside and outside the EAEU is derived from other homeopathic literature.

Based on these considerations, the authors propose to distinguish between the three categories of homeopathic medicinal products with the related requirements for Modules 4 and 5 set out in the table above.

In both the EU and the EAEU legal systems, homeopathic medicinal products not eligible for simplified registration are subject to (non-simplified) registration/authorisation. If the related requirements are met, other regulatory procedures, such as well-established applications, can also be used for homeopathic medicinal products.

Additionally, the EU allows Member States to maintain or introduce specific national requirements

57 There are more than 2.300 homeopathic medicinal products authorised based on Article 16 (2) Directive 2001/83/EC in EU Member States See, HMPWG (n 7) 50, 51. for Modules 4 and 5. Several Member States have made use of this possibility, which turned out to be very helpful for market access. ${ }^{57}$ EAEU law provides for a common EAEU standard also for Modules 4 and 5. The important but difficult interpretation of the terms and requirements introduced therein needs to take into consideration the already nationally registered homeopathic medicinal products as well as the fact that a lot of homeopathic stocks are not substance monographed in pharmacopoeias.

\section{Labelling Requirements}

According to Article 68 Directive 2001/83/EC all (authorised and registered)'homeopathic medicinal products shall be [...] identified by a reference on their labels, in clear and legible form, to their homeopathic nature'.

Furthermore, in accordance with Article 69 (1) Directive $2001 / 83 \mathrm{EC}$, the labelling and the package insert for simplified registered homeopathic medicinal products shall in addition to the clear mention of the words 'homeopathic medicinal products' bear the following information: 'homeopathic medicinal product without approved therapeutic indications' and include 'a warning advising the user to consult a doctor if the symptoms persist'.

As explained above, based on Article 16 (2) Directive 2001/83/EC, some Member States introduced or maintained national requirements. In these cases, the 
national requirements of the Member States may foresee similar language. ${ }^{58}$

For the EAEU the labelling requirements of medicinal products are stipulated in Resolution No. 76. According to Section 37d) Resolution No. 76, the word 'homeopathic' needs to be on the labelling of all homeopathic medicinal products.

The labelling requirements for homeopathic medicinal products registered according to the simplified procedure are contained in the exhaustive list set out in Section 38 Resolution No. 76. The information that the homeopathic medicinal product is without approved therapeutic indications needs to be given ${ }^{59}$ and the labelling also needs to include a warning that the user should consult a doctor if the symptoms persist. $^{60}$

Again, we can see that both legal systems (of the EU and EAEU) introduced very similar labelling requirements for homeopathic medicinal products. These labelling requirements ensure that patients receive the necessary information and advice and are aware of the medicinal products' homeopathic nature. ${ }^{61}$ The high coherency between EU and EAEU labelling requirements is very useful for market access and availability for patients.

\section{Conclusion}

The requirements for homeopathic medicinal products in the EU are based on a carefully balanced structure. There is an objective manufacturing related definition and quality and safety are guaranteed via simplified registration or marketing authorisation. At the same time, the labelling requirements ensure that patients receive the necessary information. Following the principle of method neutrality and scientific pluralism the EU legislator has created a system allowing healthcare professionals the option of treating patients with safe and high quality medicinal products of their choice. ${ }^{62}$
In 2017, the EAEU legislator introduced a regulatory framework with a very similar definition, a simplified procedure and labelling requirements. As a result, the core requirements for simplified registration are almost the same for currently altogether $33(28$ in the EU and 5 in the EAEU) countries. This high level of coherence is reasonable and should enable pharmaceutical companies to use of the same or very similar regulatory documentation for simplified but safe market access in both Unions. This legal coherence is also in the interest of patients' and healthcare professionals' demand for access of medicinal products of their choice and in the interest of competition.

In the EU, competent authorities of the Member States should, however, interpret the core requirements of simplified registration, more coherently and less restrictively than in the past. In the EAEU an already coherent application of these requirements in the early implementation phase is desirable.

In the context of (non-simplified) registration/authorisation there are similarities but also differences between the EU and EAEU law. The difficult interpretation by the Member States' competent authorities and by the Working Group issuing the related guidance documents of the terms and requirements introduced in this area in EAEU law needs to duly take into account the existence of the already nationally registered homeopathic medicinal products as well as the fact that a lot of homeopathic stocks are not substance monographed in pharmacopoeias.

\footnotetext{
58 ibid 16-18; For Germany cf Voit (n 10) 374.

59 Council of the Eurasian Economic Commission, 'The Requirements for the Labelling and Marking of Medicinal Products for Human and Veterinary Use' Resolution No 76, S 38 k.

60 ibid S 38 I.

61 Cf Voit (n 10) $374-375$.

62 Apparently this is also the current position of the European Commission which has 'no plans to revise Directive 2001/83/EC as regards homeopathic medicinal products'. Cf answer of the European Commission given to a parliamentary question on 21 June 2018, <http://europarl.europa.eu/sides/getAllAnswers.do?reference $=\mathrm{E}-2018-002348 \&$ language $=\mathrm{EN}>$ accessed 14 March 2019.
} 